\title{
Performance Investigation of a Chimney-Dependent Solar Crop Dryer for Different Inlet Areas with a Fixed Outlet Area
}

\author{
J. K. Afriyie ${ }^{1}$ and A. Bart-Plange ${ }^{2}$ \\ ${ }^{1}$ Mechanical Engineering Department, Kumasi Polytechnic, P.O. Box 854, Kumasi, Ghana \\ ${ }^{2}$ Agricultural Engineering Department, Kwame Nkrumah University of Science and Technology, Kumasi, Ghana
}

Correspondence should be addressed to J. K. Afriyie, johnafriyie2001@yahoo.com

Received 18 September 2012; Accepted 9 October 2012

Academic Editors: E. R. Bandala, F. E. Little, O. Ozgener, and K. Sumathy

Copyright (C) 2012 J. K. Afriyie and A. Bart-Plange. This is an open access article distributed under the Creative Commons Attribution License, which permits unrestricted use, distribution, and reproduction in any medium, provided the original work is properly cited.

\begin{abstract}
The paper describes the performance of a direct-mode solar crop dryer with a solar chimney. Tests were performed for three differently inclined drying-chamber roofs, each with three inlet areas for a given exit area. Cassava was used as the test crop. The results show that the increase in the inlet area for a given exit area can improve the ventilation in the dryer. However, this does not necessarily improve the drying performance of the direct-mode dryer. A wide inlet area for a given exit area can only improve the drying performance of the direct-mode dryer in a geographical location of low relative humidity. It is therefore not advisable to just copy the design of a direct-mode dryer from one location to another without regard to the ambient relative humidity. The designer and builder of the dryer must consider the relative humidity as a prime factor in the design and construction of direct-mode dryers, which are highly sensitive to the ambient relative humidity.
\end{abstract}

\section{Introduction}

The majority of the citizens of most developing countries live as rural-based farmers. The economies of those countries are heavily dependent on agriculture. The proportion of rural-based farmers in Ghana in 2004 stood at 65\% [1]. Yet, the food security remains a great challenge in developing countries. There is normally an overabundance of farm production during the harvest season. Farmers are then forced to sell their production at very cheap prices due to lack of appropriate facilities for processing and storage. The production becomes scarce off-season, even for the farmers. Such a development discourages farmers from more food in the following year. Thus, farming in the rural areas becomes increasingly unattractive. In Ghana, the youth keep drifting from the rural areas into the cities for nonexistent jobs, leading to slum development with increased crime rates. Furthermore, this problem of food insecurity affects the agricultural economy of Ghana negatively.

The farmers need to add value to their crops by drying them to reduce the moisture content to an appreciably low level so that the crops can be preserved in their prime marketable condition to enable them receive remunerative prices. The farmers normally dry their crops by spreading them on mats in the open sun. This way of crop drying is not that efficient, and the crop is exposed to rain, pest, and other forms of unhygienic conditions. Crop drying involves the removal of moisture from a crop into the surrounding air. Generally, moisture evaporates from a crop into the surrounding air whenever the vapour pressure of the moisture in the crop is higher than the partial pressure of the vapour in the air. The rate of evaporation is proportional to the pressure difference. The higher the relative humidity of the drying air, the less the pressure difference and, therefore, the less the rate of evaporation $[2,3]$. The relative humidity of the air gets lower when the temperature is increased. Crop drying then proceeds at a fast rate, when the surrounding air is warm enough and with low humidity. After moisture absorption, the air becomes more humid and needs to be replaced with fresh and less humid air to maintain the desired drying rate. Thus, an effective crop drying process requires a constant flow of appreciably warm, low-humid air through the crop. 


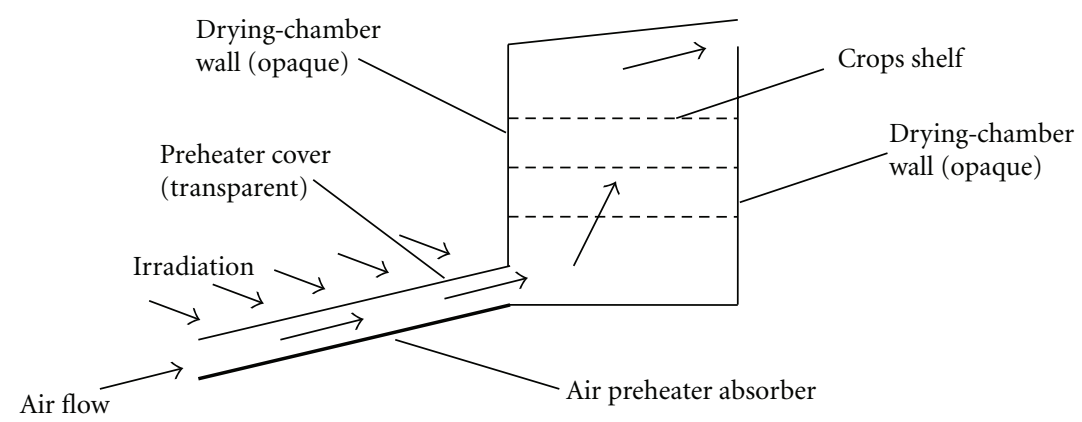

FIGURE 1: Schematic diagram of an indirect-mode cabinet dryer.

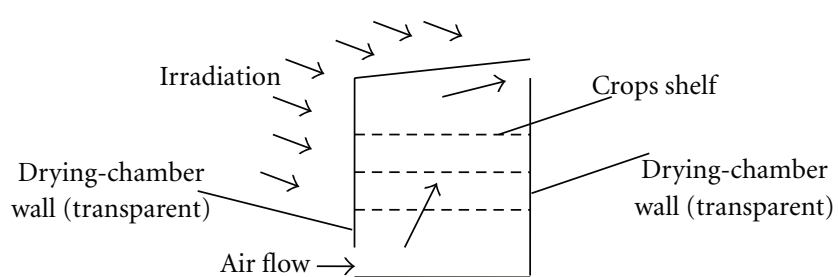

FiguRE 2: Schematic diagram of a direct-mode cabinet dryer.

A crop dryer normally requires a device to preheat the air to reduce the relative humidity en route to the crop which is housed in a drying chamber. The source of power for the heating device may be electricity, gas, diesel, biomass, or solar energy. There are two main kinds of crop dryers. One type is the forced-convection or forced-ventilation dryer which uses a blower, powered by electricity or some other mechanical means, to blow the drying air through the crop. The other type is the natural-convection or natural-ventilation dryer which depends on the natural buoyancy flow of air through the system.

Using simple and cheap natural ventilation solar crop dryers can help generate income for rural farmers, meet the present and future demand for food, and sustain the agricultural economy of most developing countries. Natural ventilation dryers are normally not too expensive to construct, and all the parts are locally available. Developing these dryers in the rural areas would also provide jobs for the artisans and youth in the rural areas and help to curb the rural-urban drift among the youth. In fact, this could be a starting point for rural industrialisation in most of the developing world. Natural ventilation solar dryers seem to be the obvious choice for rural farmers who live far away from the national electricity grid and for whom other forms of heating may also be expensive or unfriendly to the environment.

A natural ventilation solar dryer is normally one of three kinds. The indirect-mode type is equipped with a device with absorber to preheat the air en route to the drying chamber (Figure 1). The walls of the chamber are opaque to sunlight and the crops have no contact with the rays from the sun. The direct-mode dryer has no air preheater, and the radiant energy enters through the transparent walls of the drying chamber onto the drying crops which also serves as the main absorber for heating the drying air (Figure 2). The mixedmode dryer has an air preheating device and also transparent drying-chamber walls to allow maximum radiant energy absorption (Figure 3 ).

Earlier reports indicate that the direct-mode type, which depends on the contents of the drying chamber for air heating and air flow, is highly inefficient $[4,5]$. This inefficient performance is normally attributed to poor ventilation, leading to excessively high temperatures with high humidity in the drying chamber, so that the drying crops at times finally become partially cooked rather than properly dried. However, the economic base of the rural farmers is so low that most of them could only patronise this type of dryer. Further research is therefore required to come out with a direct-mode dryer designed to achieve adequate air circulation through the crop and make it more functional for effective use by the rural farmers.

Some reports on chimneys have shown that properly designed solar chimneys can boost the flow of air through an enclosure [4-11]. Afriyie et al. [12] further combined the use of a solar chimney with the effect of an appropriately inclined roof of the drying chamber to improve the ventilation in the chamber. This combination resulted in the design of the chimney-dependent solar crop dryer (CDSCD). The functional architecture of the CDSCD can be seen in Figure 4. Air enters the dryer through the bottom inlet, absorbs heat from the base and walls of the drying chamber, and dries the crops inside the chamber. The air then enters the solar chimney where it is heated to become less dense to ensure continuation of flow through the chimney into the surroundings.

The ventilation analysis is based on the underlying airflow equation [12]

$$
g \rho \beta\left(T_{\text {out }}-T_{\text {in }}\right) \Delta H=\sum K_{i} \rho \frac{v^{2}}{2} .
$$

The term on the right-hand side of (1) denotes the sum of all local losses, including those at entry and exit. Together with continuity, (1) is reformulated with respect to the inlet velocity as

$$
v_{\text {in }}=\frac{\sqrt{2 \beta g \Delta T \Delta H}}{\sqrt{K_{\text {in }}+K_{\text {roof }}\left(A_{\text {in }}{ }^{2} / A_{b} A_{\text {ch }, i}\right)+K_{\text {out }}\left(A_{\text {in }} / A_{\text {out }}\right)^{2}}} .
$$




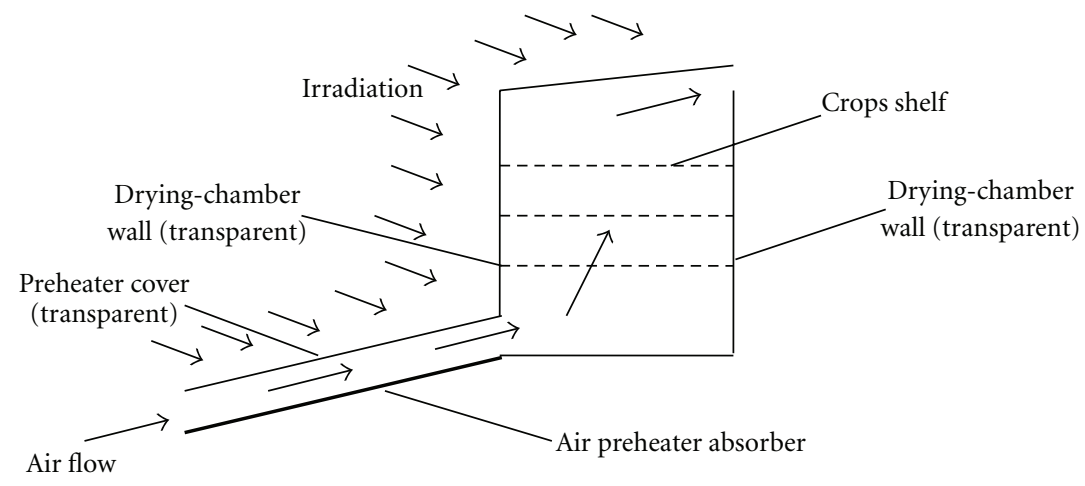

Figure 3: Schematic diagram of a mixed-mode cabinet dryer.

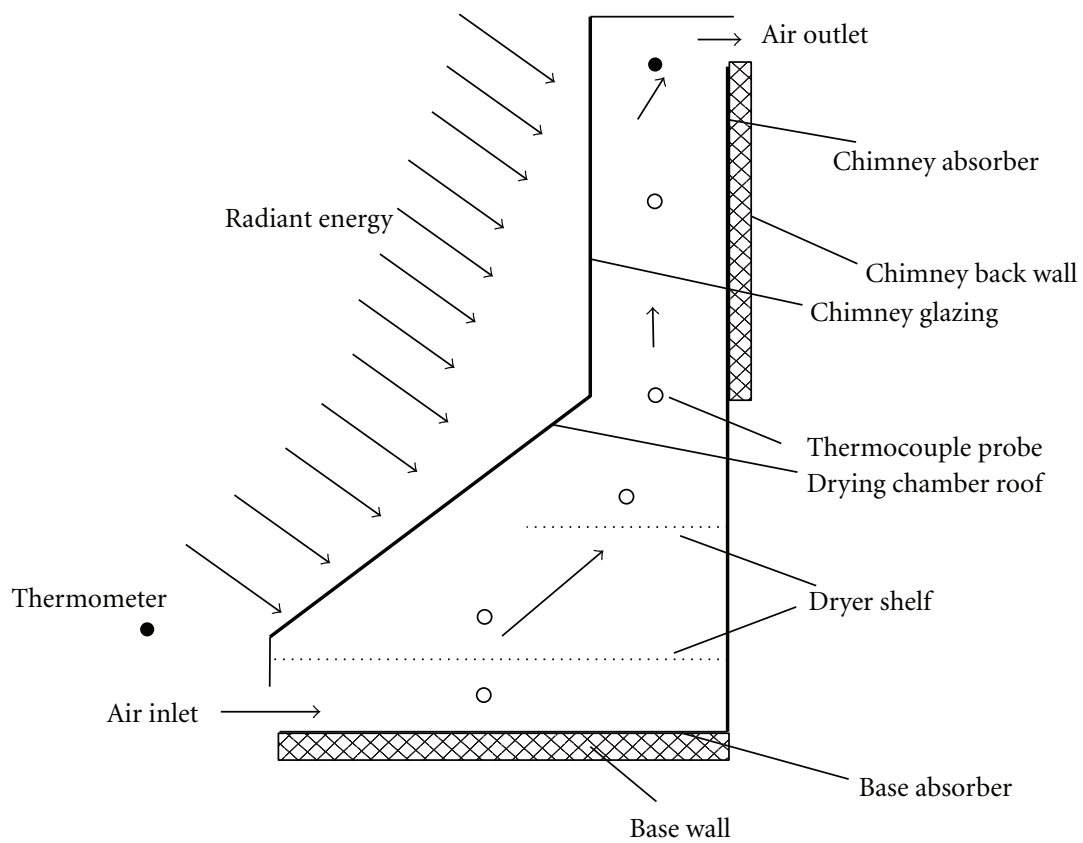

FIGURE 4: Functional architecture of the chimney-dependent direct-mode solar crop dryer.

Equation (2) can be transformed into the mass flow relation

$$
\dot{m}=\frac{\rho A_{\text {in }} \sqrt{2 \beta g \Delta T \Delta H}}{\sqrt{K_{\text {in }}+K_{\text {roof }}\left(A_{\text {in }}{ }^{2} / A_{b} A_{\text {ch }, i}\right)+K_{\text {out }}\left(A_{\text {in }} / A_{\text {out }}\right)^{2}}} .
$$

In the investigations by Afriyie et al. [12], the roof angle, and therefore the value of $K_{\text {roof }}$, was varied whilst other dimensions, including the inlet area, remained unchanged. This was combined with the chimney heating to raise the value of $\Delta T$ to improve the mass flow rate. However, the ventilation improvement achieved through this combination was not enough to improve the drying performance of the direct-mode dryer, especially in areas of high ambient relative humidity [12]. A new approach is then sought to modify the design to increase the margin of ventilation improvement. The main objective of the current study is to investigate the effect of increasing the airflow rate through the increase in the inlet area, for a given exit area, on the drying performance of the CDSCD.

\section{Methodology}

2.1. The Laboratory Model of the Dryer. A laboratory model of a direct-mode dryer was designed and constructed with three replaceable roofs for the drying chamber. These roofs were constructed at angles $81^{\circ}, 64^{\circ}$, and $51^{\circ}$ to the vertical plane. Three different inlet designs were also constructed with inlet gaps $70 \mathrm{~mm}, 50 \mathrm{~mm}$, and $30 \mathrm{~mm}$, respectively. Each inlet had a width of $390 \mathrm{~mm}$. The drying chamber had a uniform width of $440 \mathrm{~mm}$ (normal to the airflow), a length of $420 \mathrm{~mm}$ which was perpendicular to the inlet plane, and a height of $530 \mathrm{~mm}$. A steel mesh (width $=400 \mathrm{~mm}$; length $=370 \mathrm{~mm}$ ) was used as the drying shelf. The base of the chamber was made of wood ( $40 \mathrm{~mm}$ thick) with the top surface coated black to serve as absorber in the drying 


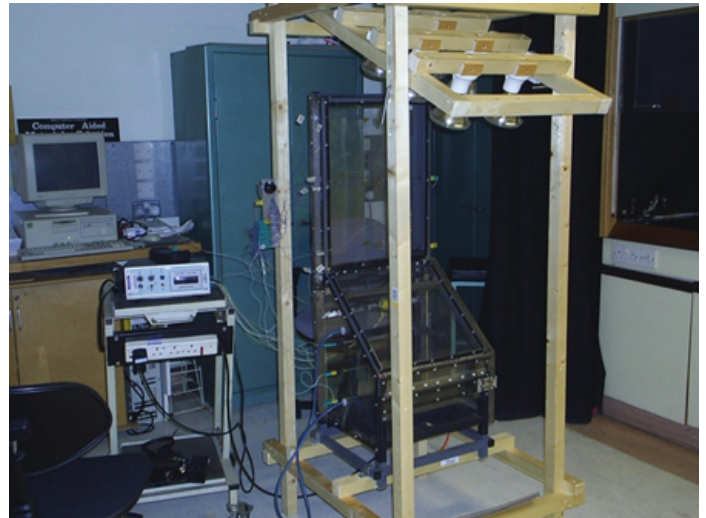

Figure 5: A setup of the dryer model for the laboratory trials.

chamber. The walls of the chamber consisted of a glazing material (Lexan sheet). The whole dryer had a uniform width of $440 \mathrm{~mm}$ (normal to the airflow).

The chimney was of rectangular cross-section of width $440 \mathrm{~mm}$ (aligned to the width of the drying chamber), uniform gap $80 \mathrm{~mm}$, and height $625 \mathrm{~mm}$. The exit had a gap of $30 \mathrm{~mm}$, a straight width of $335 \mathrm{~mm}$, and rounded ends of $15 \mathrm{~mm}$ radius. Three walls of the solar chimney were glazed. The fourth wall (back wall) was replaced with a wooden board, with the inner surface painted black to serve as solar chimney absorber.

2.2. Instrumentations Setup. To ensure a uniform irradiation for all experiments, eight infrared lamps (each $100 \mathrm{~W}$ ) were set up in front to illuminate the chimney and drying chamber, to simulate the irradiation from the sun. Thermocouple probes (type $\mathrm{K}$; range 0 to $200^{\circ} \mathrm{C}$ ) were positioned at various intervals in the air stream along the height of the dryer, as indicated in Figure 4, to measure the air temperature at these heights. Similar probes were each attached to the chimney absorber and glazing at equal heights to those in the air stream and also at the base of the drying chamber. Inlet and exit velocities were measured with a hand-held anemometer (type TA 400; range 0 to $2 \mathrm{~m} / \mathrm{s}$, logarithmic scale), and the relative humidity $(\mathrm{RH})$ at these points were measured with a hand-held thermohygrometer (type HANNA HI 8564; humidity range 10-95\%, and temperature range $0-60^{\circ} \mathrm{C}$ ). To facilitate a continuous drying process, the shelf containing the crop was weighed with a cantilever beam fixed to the top of the drying chamber and connected through a Whetstone-Bridge arrangement to a calibrated microstrain gauge (Digital Strain Indicator; type 5792). Figure 5 shows the set-up of the laboratory model, together with the instrumentations, for the trials.

2.3. Tests Overview. A total of 9 trials were performed with cassava as the drying commodity, with each trial taking a period of three days and three nights. For each trial, the lamps were switched on for 7 hours to simulate the irradiation from the sun in the day. The lamps were then switched out to allow for a possible self-drying at night. The moisture content of the crop was determined by an oven-dry method at the beginning of each trial. The mass of crop was noted in the morning before the day's drying process. The other data, together with the mass of crop were also recorded at hourly intervals during the day. The trials were grouped in three test-sets based on the roof angle, and each test-set had three trials with different inlet gaps (i.e., different inlet areas) as follows:

(1) test-set one: tests on the dryer with roof angle $81^{\circ}$, with inlet gaps $30 \mathrm{~mm}, 50 \mathrm{~mm}$, and $70 \mathrm{~mm}$;

(2) test-set two: using the roof angle $64^{\circ}$, with inlet gaps $30 \mathrm{~mm}, 50 \mathrm{~mm}$, and $70 \mathrm{~mm}$;

(3) test-set three: using the roof angle $51^{\circ}$, with inlet gaps $30 \mathrm{~mm}, 50 \mathrm{~mm}$, and $70 \mathrm{~mm}$.

\section{Results of Various Experiments}

The air velocity of the surrounding air remained almost constant between 0.1 and $0.2 \mathrm{~m} / \mathrm{s}$ for all the trials. The ambient $\mathrm{RH}$, mass flow rate, and the moisture content values are plotted against the drying time in Figures 6, 7, and 8 for the roof angles $81^{\circ}, 64^{\circ}$, and $51^{\circ}$, respectively. The time axis of each graph has 0 to 7 hours for the first day of drying, 7 to 14 hours for the second day, and 14 to 21 hours for the third day.

As can be seen in Figures 6(a), 7(a), and 8(a), the ambient $\mathrm{RH}$ varied from one trial to another and also during the course of each drying process. Trials for the dryer with inlet gap $70 \mathrm{~mm}$ generally had the highest mass flow through the dryer, followed by those with inlet gaps $50 \mathrm{~mm}$ and $30 \mathrm{~mm}$, as shown in Figures 6(b), 7(b), and 8(b). The changes in moisture content (MC) with drying time are shown in Figures 6(c), 7(c), and 8(c). The sloping paths of these curves indicate the drying processes during the day, and the vertical lines represent the self-drying processes at night (Figures $6(\mathrm{c}), 7(\mathrm{c})$, and $8(\mathrm{c}))$. The moisture drop was always highest during the first day of each drying process, whilst the last day recorded the lowest drop in moisture content.

The temperature of the environment varied from one trial to another. So the Temperature Rise Above Ambient (obtained by subtracting the ambient temperature from the temperature at various heights in the dryer) was used to compare the temperature rise at corresponding heights. This method cancelled out the effects of the external temperature variations. Graphs of the Temperature Rise Above Ambient have been presented against the heights in the dryer in Figure 9. The heights of 6,16 , and $26 \mathrm{~cm}$ are heights in the drying chamber. Height $49 \mathrm{~cm}$ is at the exit of the drying chamber and inlet of the solar chimney. Height $84 \mathrm{~cm}$ is inside the chimney and height $109 \mathrm{~cm}$ is at the exit of the chimney. The experimental set up had no control over the ambient relative humidity which kept on changing from one drying day to another and also within each drying day. However, its effects on the outcomes together with all the results are discussed in Section 4. 


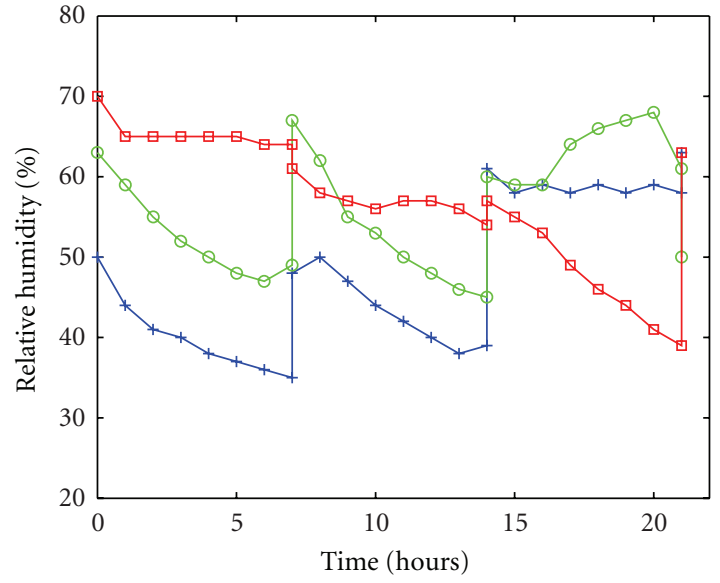

(a) Ambient relative humidity versus drying time

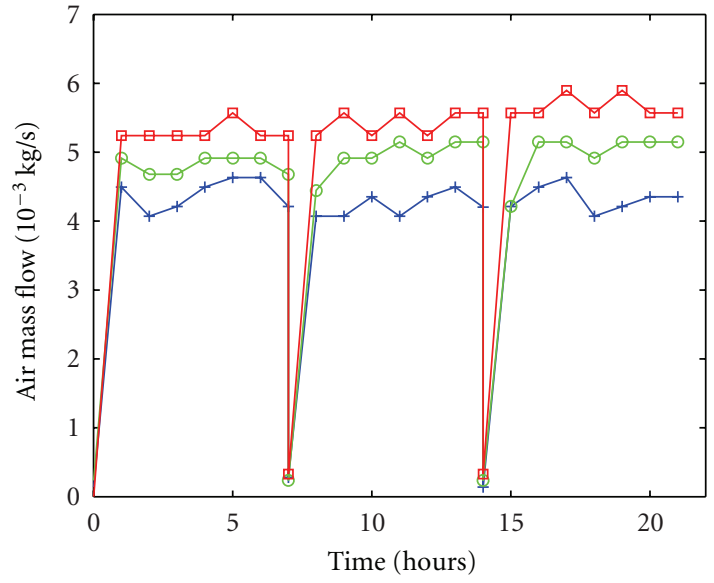

(b) Air flow rate versus drying time

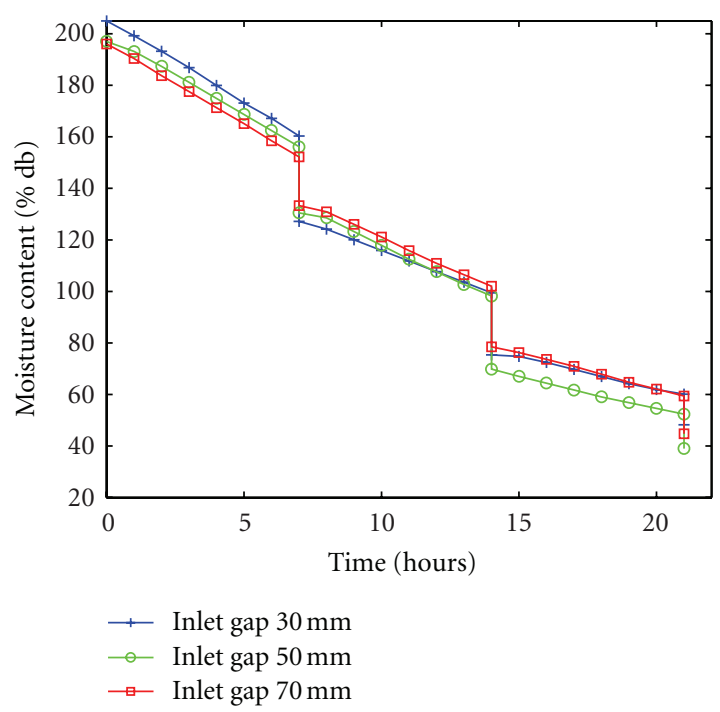

(c) Moisture content versus drying time

FIGURE 6: Ambient relative humidity and drying performance of the dryer with roof angle $81^{\circ}$.

\section{Discussion of the Results}

For each trial, the best drying performance (indicated by the drop in MC) always occurred during the first day when the MC was high. The drying process on this day depended strongly on airflow for removing loosely held moisture from the crops surfaces $[13,14]$. Drying at later stages, as the moisture content reduced, depended more on the heat energy required to evaporate the strongly bound moisture from within the crop [15]. Lowest MC drops were observed on day 3 , due to low moisture content and low temperature in the drying chamber. During night when the lamps were switched off, self-drying occurred from the energy stored by the dryer during the day. The conditions inside the dryer (including the mass flow of air) fell to atmospheric values by the start of drying the next morning.

4.1. Dryer with Roof Angle $81^{\circ}$. In spite of the lowest mass flow rate of air through dryer with roof angle $81^{\circ}$, inlet $30 \mathrm{~mm}$ (Figures 6(b), 7(b), and 8(b)), it had better performance than those of higher inlet areas of the same roof angle during the first day of drying (Figure 6(c)). This is attributable to the low ambient $\mathrm{RH}$ of roof angle $81^{\circ}$, inlet $30 \mathrm{~mm}$, which was widely below those of the other two which started the day in an environment above $60 \% \mathrm{RH}$ (Figure 6(a)). The RH for inlet gap $50 \mathrm{~mm}$ fell in the course of the day to below $60 \%$, but the effect was not enough to overcome the mass flow effect (Figure 6(b)) of the inlet gap $70 \mathrm{~mm}$. The moisture drop for inlet gap $30 \mathrm{~mm}$ was still the best during the first night as indicated in Figure 6(c) due to the low RH (Figure 6(b)). On day 2, the difference in $\mathrm{RH}$ had reduced slightly. So the mass flow effect, although not so strong on day 2, was enough to cause the MC drop of inlet gap $50 \mathrm{~mm}$ to be better than that of inlet gap $30 \mathrm{~mm}$. The RH of inlet gap $70 \mathrm{~mm}$ was around $60 \%$ for the most of day 2 and so the performance was slightly lower than that of inlet gap $50 \mathrm{~mm}$. The dryer with inlet gap $70 \mathrm{~mm}$ began the third day with the highest MC of $78.51 \% \mathrm{db}$. The effect 


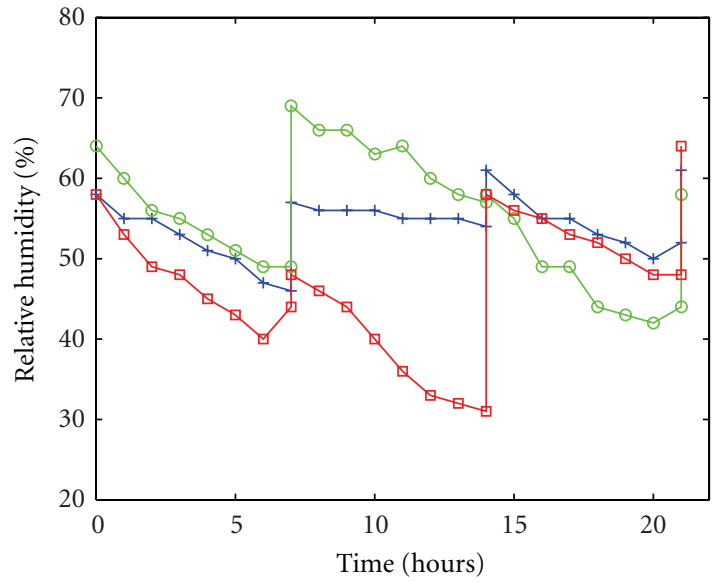

(a) Ambient relative humidity versus drying time

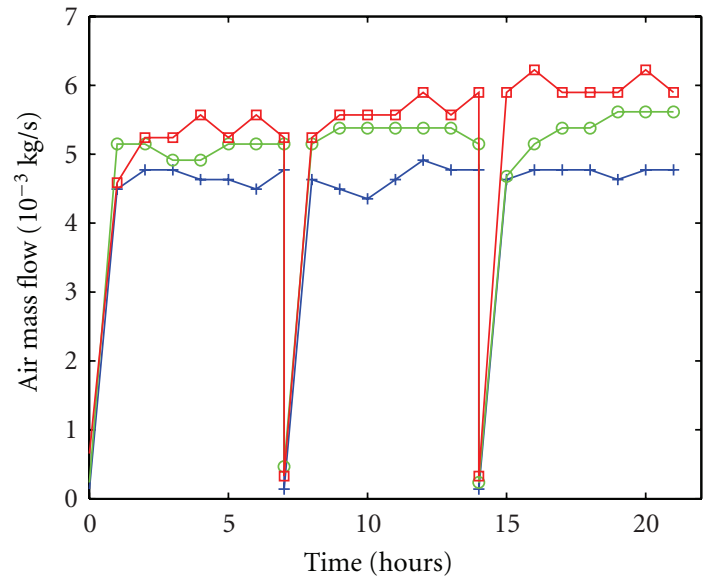

(b) Air flow rate versus drying time

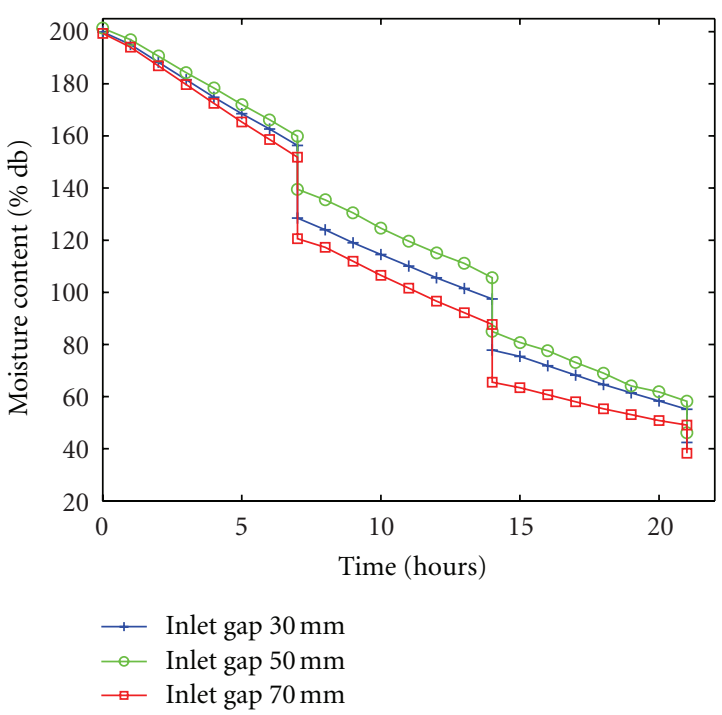

(c) Moisture content versus drying time

FIGURE 7: Ambient relative humidity and drying performance of the dryer with roof angle $64^{\circ}$.

of highest air flow had waned on this day when the drying process depended more on heat transfer than airflow. The much lower RH caused a high MC drop of $19.09 \% \mathrm{db}$ for inlet gap $70 \mathrm{~mm}$. However, this drop was not enough, ending the third day at MC of $78.51 \% \mathrm{db}$, as against $69.89 \% \mathrm{db}$ and $75.36 \% \mathrm{db}$ for inlet gaps $50 \mathrm{~mm}$ and $30 \mathrm{~mm}$, respectively.

4.2. Dryer with Roof Angle $64^{\circ}$. The roof angle $64^{\circ}$ with inlet gap $70 \mathrm{~mm}$ showed better performance on day 1 than other inlet gaps of the same roof angle (Figure $7(\mathrm{c})$ ). This is attributable to a combination of high mass flow (Figure 7(b)) and low ambient RH (Figure 7(a)). Inlet gap $30 \mathrm{~mm}$ did better than inlet gap $50 \mathrm{~mm}$ on this day. This could be due to the fact that the inlet gap $50 \mathrm{~mm}$ started in an ambient $\mathrm{RH}$ above $60 \%$ and the RH stayed above that of inlet gap $30 \mathrm{~mm}$ throughout the day. Another factor could be the relatively higher temperature of the drying air through the inlet gap $30 \mathrm{~mm}$ before the air encountered the crop, which is discussed subsequently. On day 2 , the $\mathrm{RH}$ of inlet $50 \mathrm{~mm}$ is higher, but the MC drop was higher than those of inlet gaps $30 \mathrm{~mm}$ and $70 \mathrm{~mm}$, as the inlet gap $50 \mathrm{~mm}$ operated with higher MC levels (i.e., from 139.53 to $105.63 \% \mathrm{db}$ ), as against the levels of 128.48 to $97.45 \% \mathrm{db}$ and 120.59 to $87.67 \% \mathrm{db}$ for inlet gaps $30 \mathrm{~mm}$ and $70 \mathrm{~mm}$, respectively. With all the trials of day 3 taking place in an ambient $\mathrm{RH}$ below $60 \%$ (Figure $7(\mathrm{a})$ ) when the mass flow effect had also waned, high MC levels continued to dictate the moisture reduction as indicated in Figure 7(c). The fast drying rates associated these high MC levels could however not allow the final MCs of inlet gaps $30 \mathrm{~mm}$ and $50 \mathrm{~mm}$ to overtake that of inlet gap $70 \mathrm{~mm}$ which ended the process at MC of $38.28 \%$ $\mathrm{db}$, as against $42.43 \% \mathrm{db}$ and $46.12 \% \mathrm{db}$ for inlet gaps $30 \mathrm{~mm}$ and $50 \mathrm{~mm}$, respectively.

4.3. Dryer with Roof Angle $51^{\circ}$. Mass flow rate of air was mostly the deciding factor in the trials with roof angle $51^{\circ}$, as all the trials occurred mostly in an ambient RH of less than $60 \%$, especially within the first two days. In all the trials, 


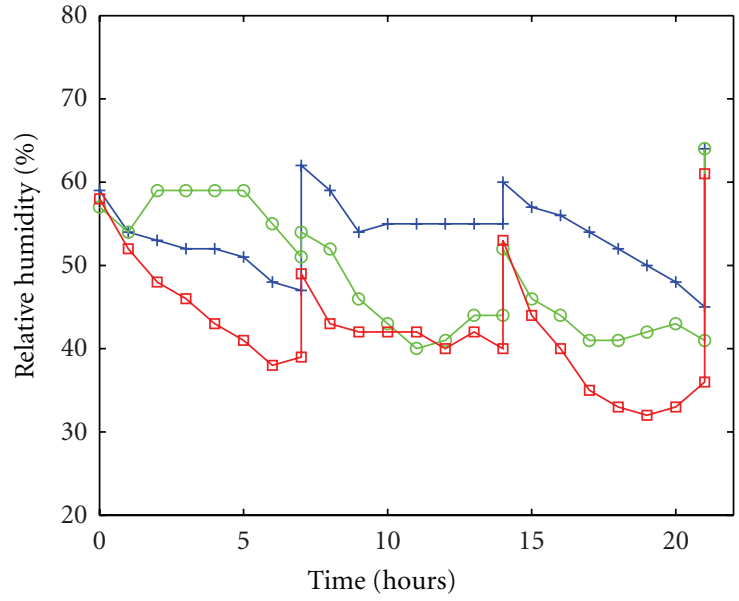

(a) Ambient relative humidity versus drying time

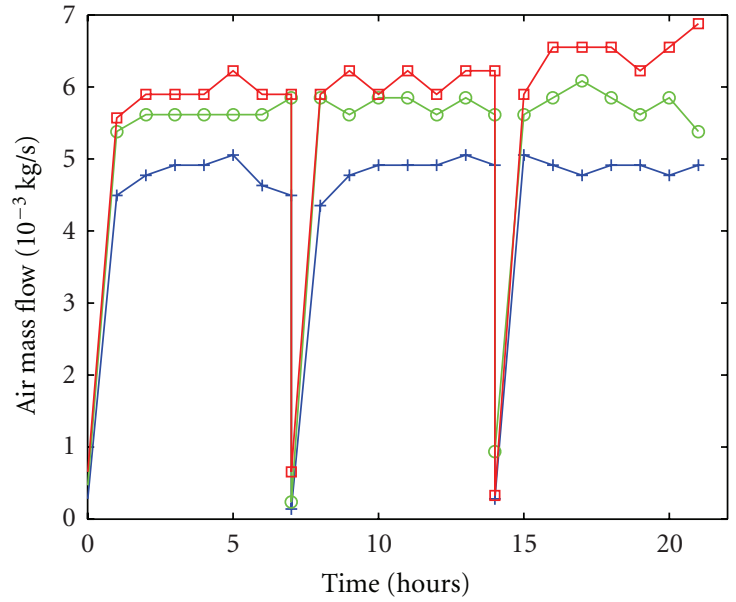

(b) Air flow rate versus drying time

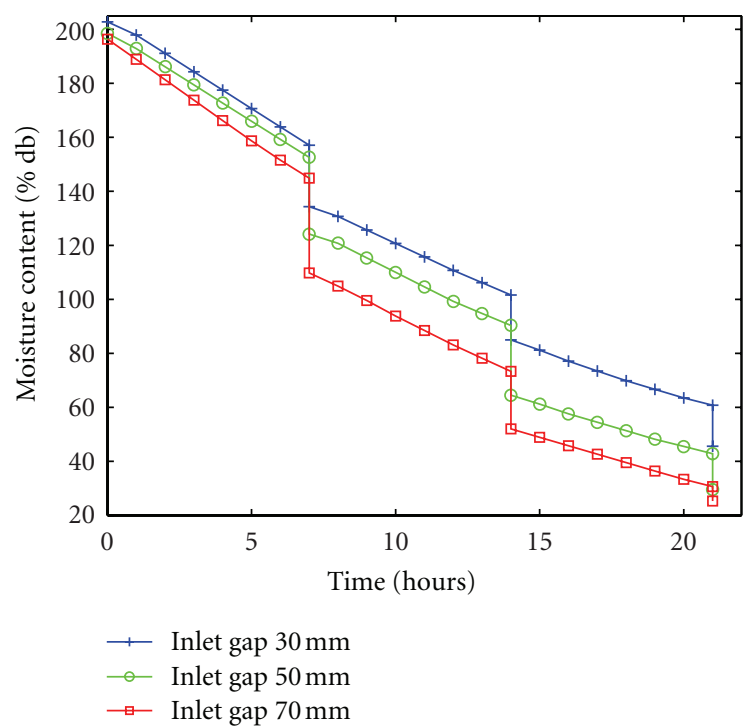

(c) Moisture content versus drying time

FIGURE 8: Ambient relative humidity and drying performance of the dryer with roof angle $51^{\circ}$.

the dryer with roof angle $51^{\circ}$ and inlet gap $70 \mathrm{~mm}$ showed the best performance, from the combination of low ambient $\mathrm{RH}$ and high mass flow rate (Figure 8).

4.4. Temperatures at Various Points in the Dryer. The air temperature inside the dryer rose as the air flowed upwards through the dryer. As expected with all ventilation processes, the temperature in the drying chamber was lowest for inlet gap $70 \mathrm{~mm}$ where the mass flow was highest (Figure 9). The drying chamber was quite a distance from the lamps during the laboratory experimentations and the temperatures were therefore generally low in the chamber, especially at the height of $6 \mathrm{~cm}$ which was below the drying crop. The temperature at this point sometime fell below ambient, in the case of high inlet gaps, and thus raised the $\mathrm{RH}$ before the drying air encountered the crop. The heat energy that trickled down through the crops was not enough to heat the air in this area, especially where the mass flow is high. This could be a factor to the sometimes better drying performance observed for the inlet gap $30 \mathrm{~mm}$ than that of inlet gap $50 \mathrm{~mm}$.

Thus, to sum up the above discussions, high inlet gaps for a given exit gap can provide a wide inlet opening which can result in high mass flow rate. This can complement the use of a solar chimney and appropriate roof angle of the drying chamber for ventilation improvement in the chamber. However, unlike in the case of the indirect-mode and the mixed-mode dryers where the air is adequately preheated to reduce the relative humidity en route to the drying chamber, using this design combination of inlet, roof angle, and solar chimney did not always result in improved drying process of the direct-mode dryer. The combination can only be effective for improving the performance of the direct-mode dryer when the relative humidity is below a certain value (about $60 \%$ for cassava). It is therefore not advisable to just copy the design of a direct-mode dryer from one geographical 

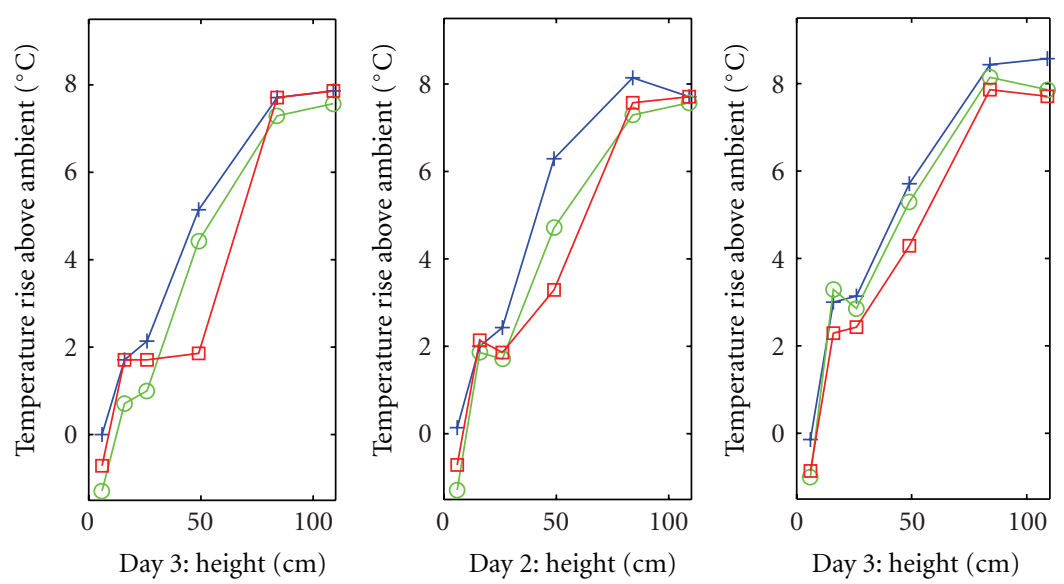

(a) For the dryer with roof angle $81^{\circ}$
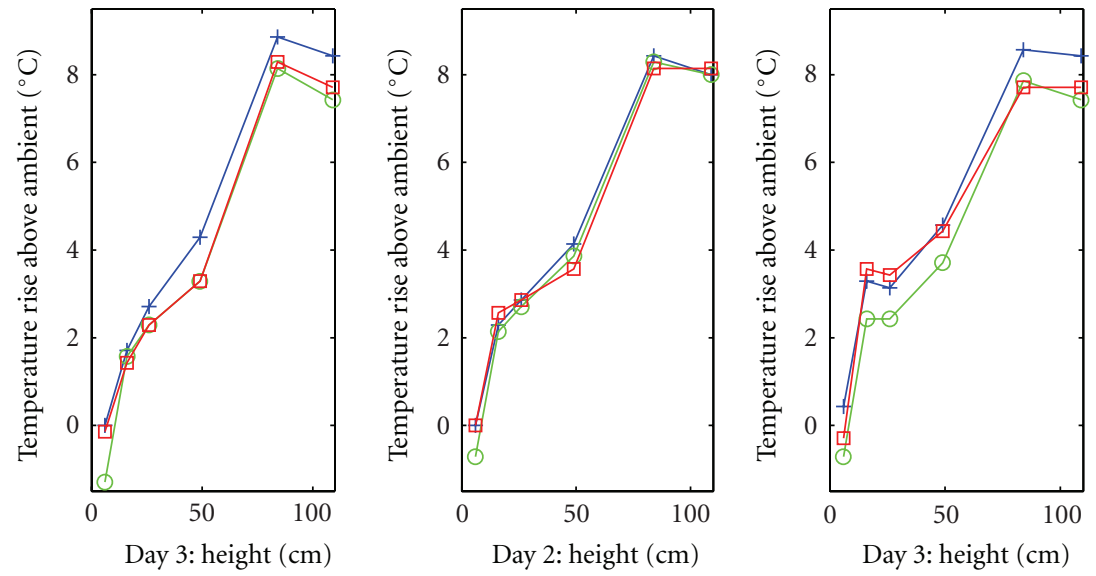

(b) For the dryer with roof angle $64^{\circ}$
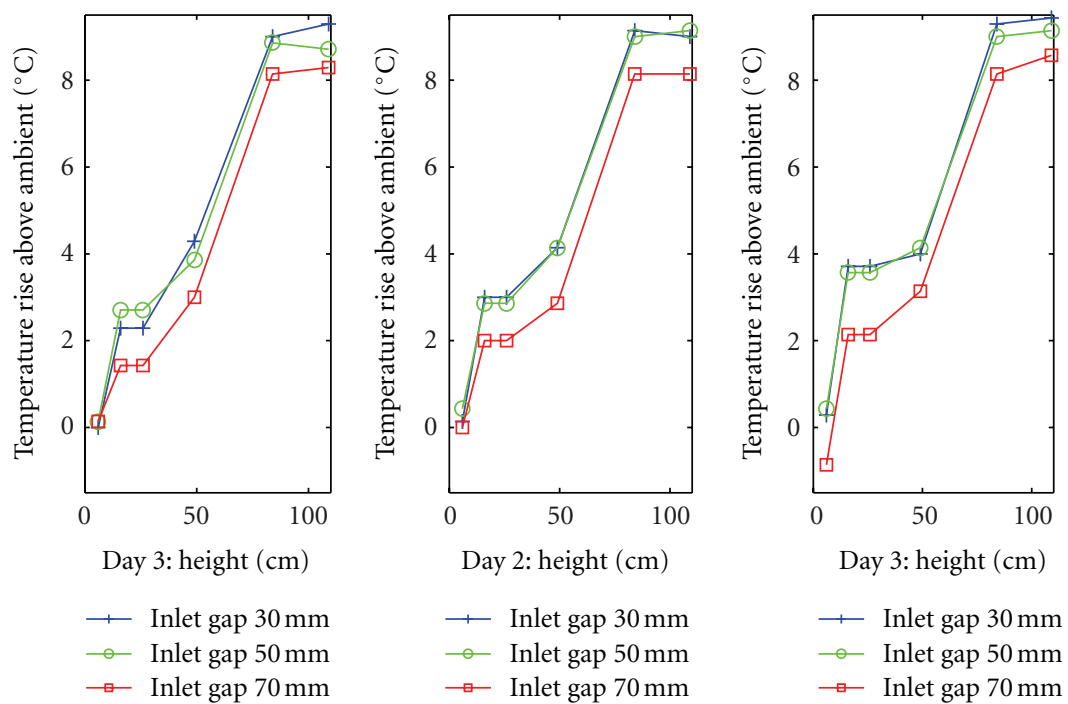

(c) For the dryer with roof angle $51^{\circ}$

FIGURE 9: Temperature rise above ambient at various heights of the dryer. 
location to another without regard to the relative humidity of the area. In areas of high relative humidity, other designs like the internal arrangements of the crops become necessary.

\section{Conclusion}

The experimental trials have shown that the inlet area of the direct-mode dryer can be set appropriately together with the use of a solar chimney and a suitable angle of the roof of drying-chamber to improve the ventilation through the dryer. However, this combination would only be effective for improving the drying performance of the direct-mode dryer in areas of low relative humidity, as the direct-mode dryer is highly sensitive to the environmental relative humidity. In all the trials, the dryer with roof angle $51^{\circ}$ and inlet gap $70 \mathrm{~mm}$ showed the best performance, from the combination of low ambient RH and high mass flow rate. It is therefore not advisable to just consider the low cost of construction and material availability and copy the design of the directmode dryer from one geographical location to another based only on the improved air flow rate from the solar chimney, drying-chamber-roof angle, and the inlet gap. Due regard must be given to the local relative humidity of the area during the design of the dryer. Where the ambient RH is persistently high, other measures such as the internal crop arrangements become necessary.

\section{Nomenclature}

$v_{\text {in }}:$ Inlet air velocity

$\beta$ : Bulk coefficient of expansion of air

g: Acceleration due to gravity

$\Delta T$ : Dryer inlet to outlet temperature difference

$\Delta H$ : Dryer inlet to outlet height difference

$K_{\text {in }}$ : Dryer inlet pressure coefficient

$A_{b}$ : Drying chamber base area

$A_{\text {ch, }, i}:$ Chimney inlet area

$A_{\text {in }}$ : Dryer inlet area

$A_{\text {out }}$ : Chimney outlet area

$K_{\text {out }}$ : Chimney outlet pressure coefficient

$K_{\text {roof: }}$ Pressure coefficient at drying chamber roof

$\rho: \quad$ Average air density in the whole structure

$\dot{m}$ : The mass flow rate of air through the dryer.

\section{References}

[1] K. Owusu-Baah, Workshop on ECOWAS policy, 2004, http:// www.ghaweb.com.

[2] G. F. C. Rogers and Y. R. Mayhew, Engineering Thermodynamics, Work and Heat Transfer, Longman Scientific, 4th edition, 1992.

[3] D. Jain and G. N. Tiwari, "Effect of greenhouse on crop drying under natural and forced convection I: evaluation of convective mass transfer coefficient," Energy Conversion and Management, vol. 45, no. 5, pp. 765-783, 2004.

[4] O. V. Ekechukwu and B. Norton, "Design and measured performance of a solar chimney for natural-circulation solarenergy dryers," Renewable Energy, vol. 10, no. 1, pp. 81-90, 1997.
[5] O. V. Ekechukwu and B. Norton, "Review of solar-energy drying systems II: an overview of solar drying technology," Energy Conversion and Management, vol. 40, no. 6, pp. 615-655, 1999.

[6] Z. D. Chen, P. Bandopadhayay, J. Halldorsson, C. Byrjalsen, P. Heiselberg, and Y. Li, "An experimental investigation of a solar chimney model with uniform wall heat flux," Building and Environment, vol. 38, no. 7, pp. 893-906, 2003.

[7] K. S. Ong, "A mathematical model of a solar chimney," Renewable Energy, vol. 28, no. 7, pp. 1047-1060, 2003.

[8] K. S. Ong and C. C. Chow, "Performance of a solar chimney," Solar Energy, vol. 74, no. 1, pp. 1-17, 2003.

[9] N. K. Bansal, J. Mathur, S. Mathur, and M. Jain, "Modeling of window-sized solar chimneys for ventilation," Building and Environment, vol. 40, no. 10, pp. 1302-1308, 2005.

[10] P. Chantawong, J. Hirunlabh, B. Zeghmati, J. Khedari, S. Teekasap, and M. M. Win, "Investigation on thermal performance of glazed solar chimney walls," Solar Energy, vol. 80, no. 3, pp. 288-297, 2006.

[11] A. G. Ferreira, C. B. Maia, M. F. B. Cortez, and R. M. Valle, "Technical feasibility assessment of a solar chimney for food drying," Solar Energy, vol. 82, no. 3, pp. 198-205, 2008.

[12] J. K. Afriyie, M. A. A. Nazha, H. Rajakaruna, and F. K. Forson, "Experimental investigations of a chimney-dependent solar crop dryer," Renewable Energy, vol. 34, no. 1, pp. 217-222, 2009.

[13] O. V. Ekechukwu, "Review of solar-energy drying systems I: an overview of drying principles and theory," Energy Conversion and Management, vol. 40, no. 6, pp. 593-613, 1999.

[14] M. R. Okos, G. Narsimhan, R. K. Singh, and A. C. Weitnauer, "Food dehydration," in Handbook of Food Engineering, D. R. Heldman and D. B. Lund, Eds., pp. 437-562, Marcel Dekker, New York, NY, USA, 1992.

[15] A. S. Mujumdar, "Drying fundamentals," in Industrial Drying of Foods, C. G. J. Baker, Ed., pp. 7-30, Blackie Academic \& Professional, London, UK, 1997. 

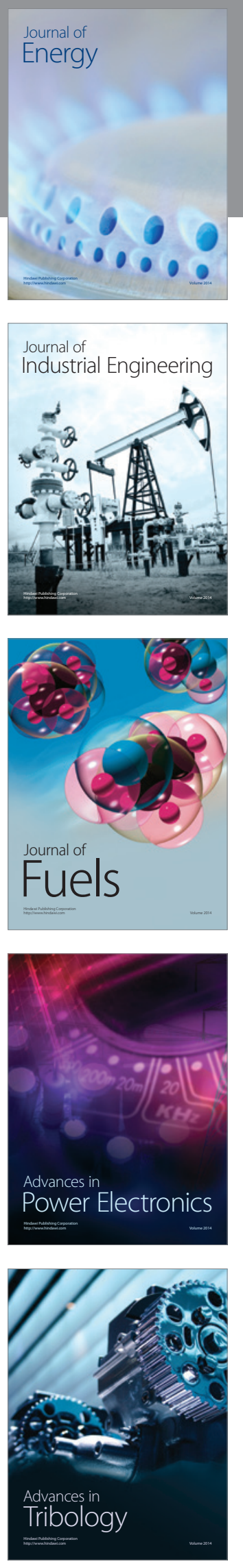
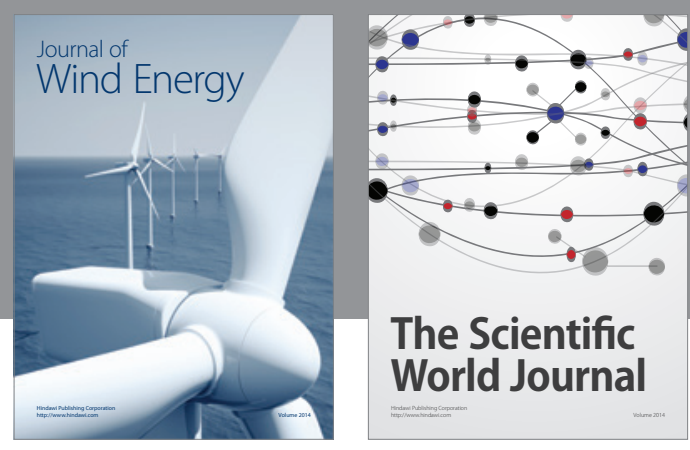

The Scientific World Journal

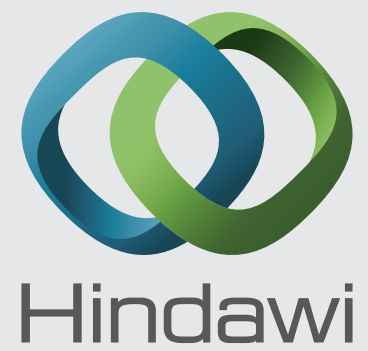

Submit your manuscripts at http://www.hindawi.com
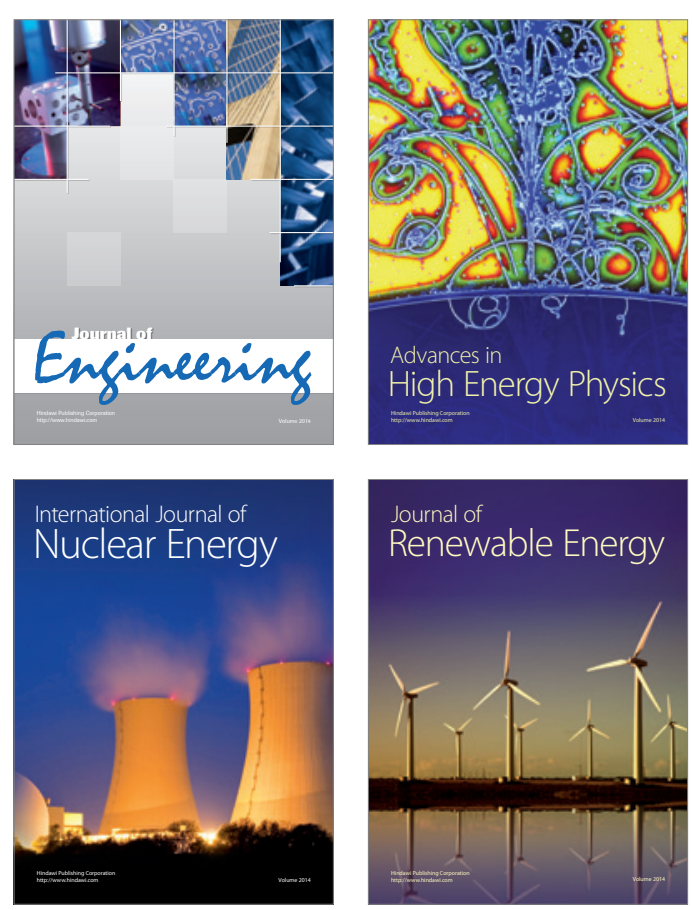

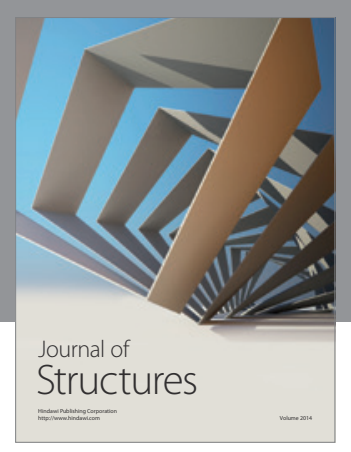

Rotating
Mechinery
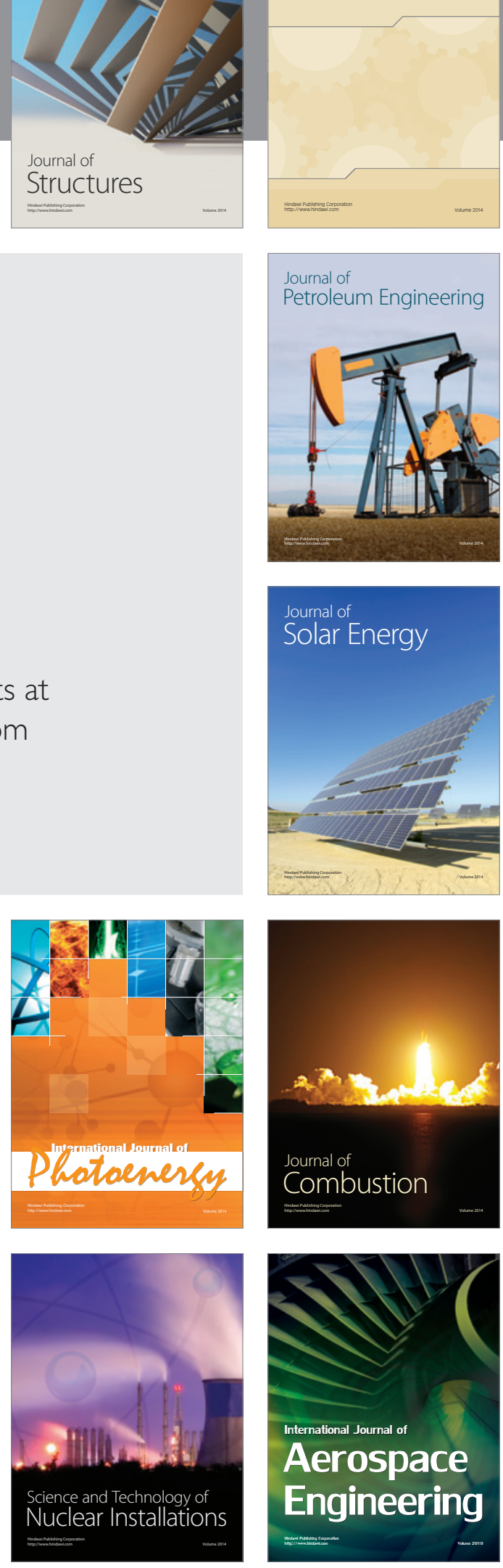